\title{
علاقة تسامي الذات بالاستقرار النفسي لاى طلبة الجامعة
}

\section{أ.د. آمال اسماعيل حسين}

كلية التربية / الجامعة المستنصرية

Em=amalesmael2017@gmail.com

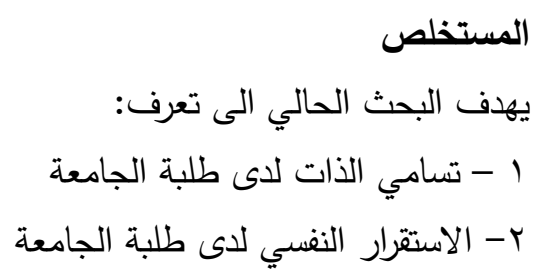

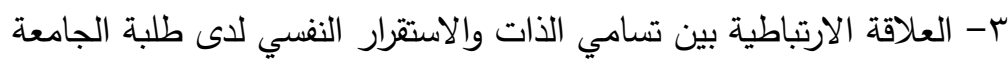

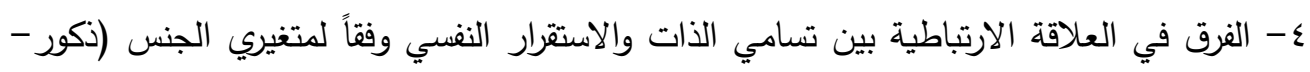

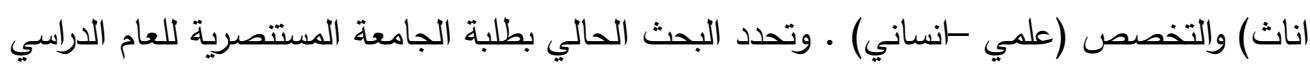
(Y.Y.Y.Y.Y.) وقامت الباحثة ببناء مقياس تسامي الذات يتكون من ع ب( فقرة ) وكذلك بناء مقياس الاستقرار النفسي

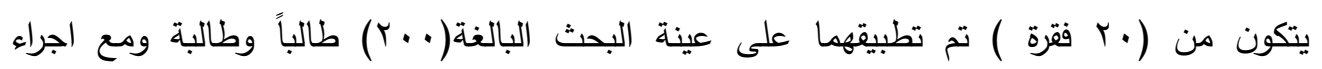

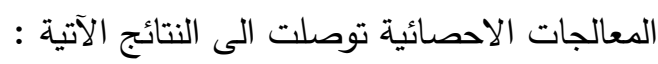
1- وجود سمة التسامي لدى طلبة الجامعة r- وجود الاستقرار النفسي لدى طلبة الجامعة

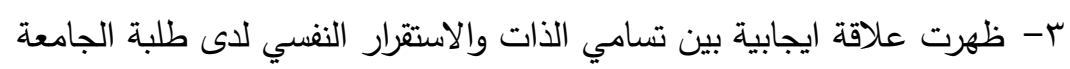

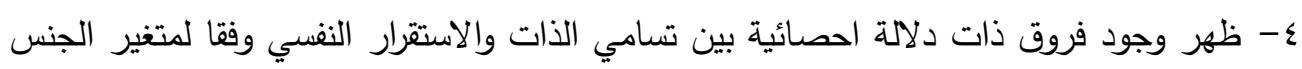

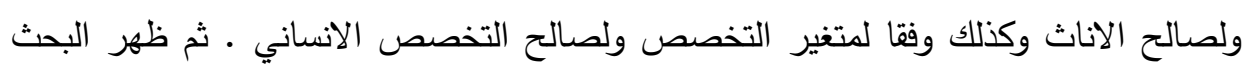

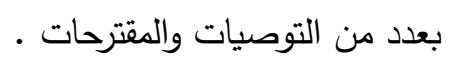

الكلمات المفتاحية : تسامي الذات الاستقرار النفسي طلبة الجامعة ولتية 
العزء الزع ابع والأربعون

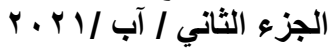

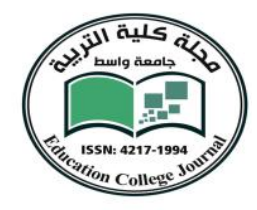

The relationship of self-transcendence to psychological stability among university students

\section{Professors Dr. Amal Ismail Hussein \\ College of Education/Al-Mustansiriya University \\ Em=amalesmael2017@gmail.com}

\section{Extract}

The current research aims to know:

1 - Self-transcendence among university students

2- Psychological stability of university students

3- The correlation between self-transcendence and psychological stability among university students

4- The difference in the correlation between self-transcendence and psychological stability according to the variables of sex (male - female) and specialization (scientific - human). The current research is determined by the students of Al-Mustansiriya University for the academic year (2020-2021) for both sexes (male - female) and for the two specializations (scientific human). ) for the morning study. The researcher built a self-transcendence scale consisting of 24 items, as well as building a psychological stability scale consisting of (20 items) that were applied to the research sample of (200) male and female students. After conducting statistical treatments, the following results were obtained:

1 - The presence of the trait of sublimation among university students

2- The presence of psychological stability among university students

3- A positive relationship appeared between self-transcendence and psychological stability among university students

4- There were statistically significant differences between self-transcendence and psychological stability according to the variable of sex and in favor of females, as well as according to the variable of specialization and in favor of human specialization. Then the research appeared with a number of recommendations and suggestions.

key words: self sublimation psychological stability university students 
نتيجة التطور السريع لوسائل الحياة في الوقت الحالي وانشغال الفرد فيها لوحظ هنالك تغيير في سلوكياته وطبائعه ومن بين هذه السلوكيات تسامي الذات الذي يعد من المتغيرات المهمة في شخصية الفرد وسموه ورقيه اذ يعني توجيه القوة النفسية الى عمل الخير المطلق الذي يجعل منه فرداً صافياً

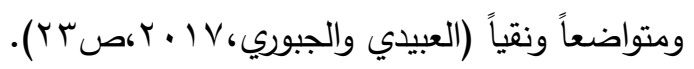

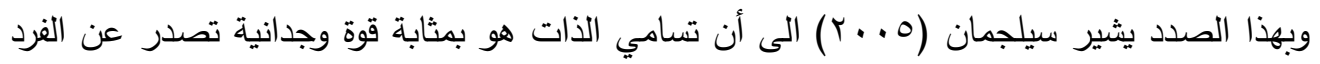
وتجعله مرتبطاً بأشياء أكبر وتجعله متصلاً بالأخرين وبالمستقبل، كما توسع علاقته مع ال أفراد ومع البيئة ليصبح أكثر تكيفاً واستقرارا ، أي أن الأفراد بحاجة الى سمة تسامي الذات من اجل

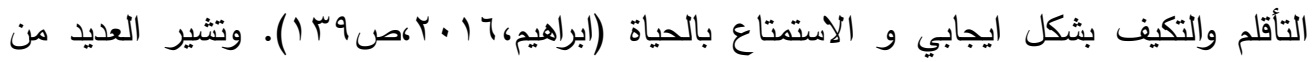
الدراسات الى ان الأفراد الذين لديهم مشكلات نفسية يتسمون بضعف تسامي الذات بالمقارنة مع الاخرين ، كما تثير العديد من الدراسات ومنها دراسة (clonniger,1993) الى ان صفات الفرد غير المتسامي ذاتياً هو التفاخر بالذات والتعالي والنرجسية كما يظهر سوء التوافق في التعامل مع المواقف الصعبة ونادراً مايقدم تضحيات من أجل الاخرين (clonniger,1993,p.833) اما الافراد الذين يتمتعون بتسامي الذات فانهم غالبا ما يكونون ايجابيون ويميلون الى مساعدة الآخرين

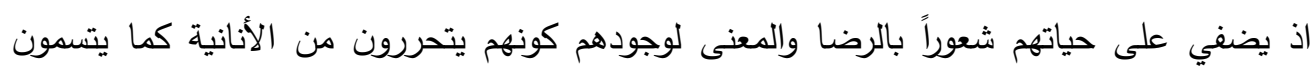
بالايجابية والحيوية والاستقرار النفسي ( wong,2016,p.88) فالاستقرار النفسي هو حالة ايجابية تعكس تمتع الفرد بالرضا عن نفسه وعن علاقاته بالآخرين مع

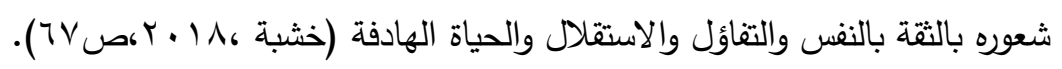
وقد اشارت دراسة ليفجر( .... الى) أن الاستقرار النفسي له تأثير واضح وكبير على المشاعر

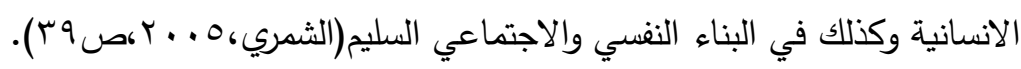
أما الفرد غير المستقر نفسياً فأنه يشعر بأن بيئته مهددة وأن الأذى سيلحق به في أي وقت كما انه يشعر بالخوف من المستقبل ويتوقع حصول الخطر ويفقد الثقة بالآخرين ويتحفظ في علاقاته

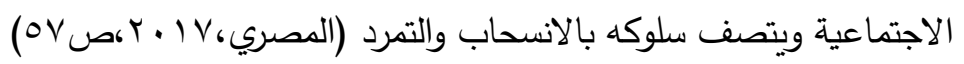
وترى الباحثة أن تزايد الضغوط وتفاقم مشكلات الحياة مما يبعث لدى الطلبة حالة من عدم الاستقرار

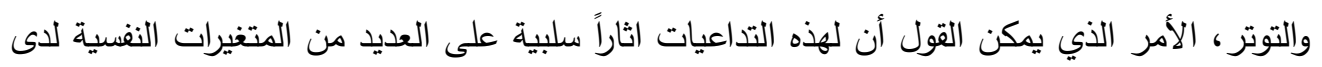
الطلبة كالاستقرار النفسي وتسامي الذات ومتغيرات اخرى ذات علاقة بهذه التحديات . ومن هنا تتجلى مشكلة البحث الحالي من خلال الاجابة عن التساؤل الآتي: 


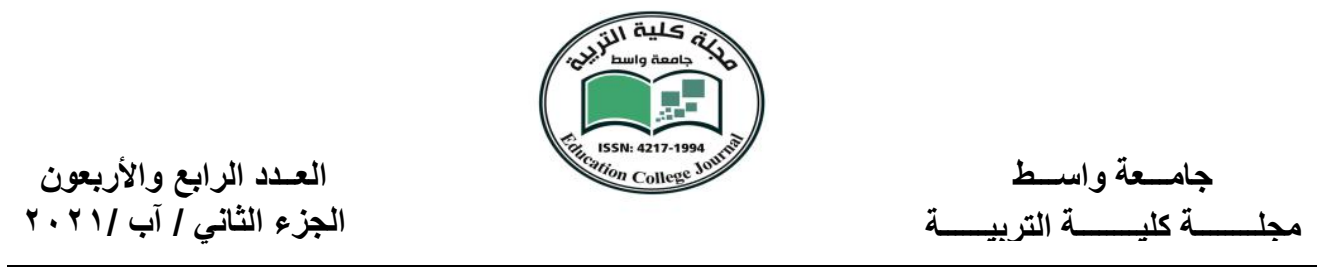

"هل هنالك علاقة بين تسامي الذات والاستقرار النفسي لدى طلبة الجامعه"

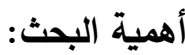

أن تسامي الذات يعد اساساً جوهرياً للصحة النفسية، كما يمثل قوة نفسية واجتماعية في اتجاه النضج الذاتي والاجتماعي وتشمل الجهود التي تقدم في سبيل احترام الذات - ( Haugan,et al,2012,P.22 )

كما يعد تسامي الذات من المكونات الأساسية في بناء القوى الداخلية للفرد و يعطي القدرة على

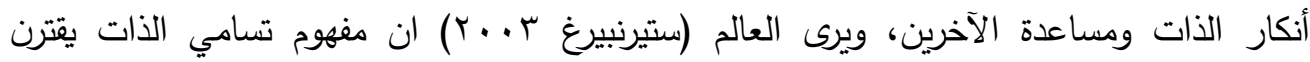
بالحكمة والتي تعتمد على الذكاء والابداع الشخصي للفرد في تطبيق القيم التي تخدم الصالح العام ، أي الموازنة بين مايملكه الفرد داخلياً وماتتطلبه البيئة خارج الذات الى أن يستطيع تدريجياً تقوق ماهو خارجي عما هو داخلي فيعيش الفرد حياته في الغالب خارج ذاته ويقدم مصلحة الهجتمع على

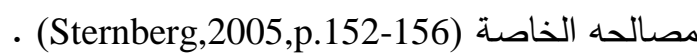

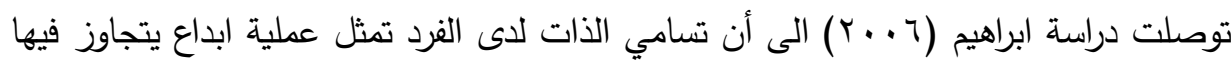
الفرد نفسه ويرتقع عن العشوائية والسلبية في وجوده الى السعي والغائية والحرية ، أي ان تسامي

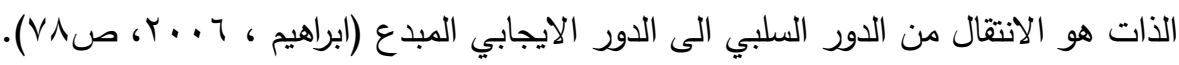
ويرى العالم سلجمان (0. . ب) الى ان تسامي الذات ينطوي تحت مجال علم النفس الايجابي فهو بمثابة قوة وجدانية تصدر من الفرد وتربطه بأشياء أكثر وأكبر كما تصله وتربطه بالأفراد الآخرين

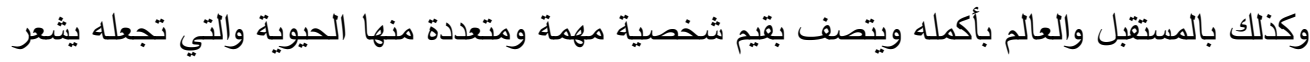
بالطاقة والقوة الداخلية ويبعث الحيوية عند الاخرين وكذلك يتصف بالمرح والامل والتفاؤل والتسامح

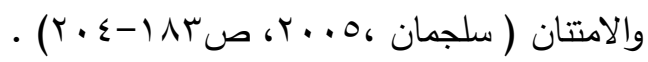

وقد توصلت دراسة جوارد(79 199 ) الى وجود علاقة ايجابية بين تسامي الذات والرضا عن الحياة

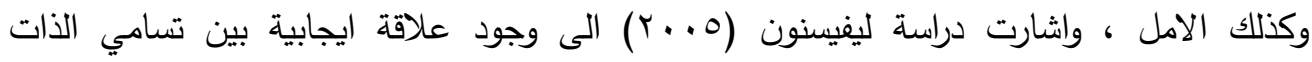
والرفاهية النفسية ونوعية الحياة كما وجدت ان تسامي الذات له دور كبير وواضح بين التوجه نحو القيم الاجتماعية لدى الافراد وشعورهم بالاستقرار النفسي ،أذ يعد اساسا نظريا لتطوير وتوسيع تدخلات فاعلة لتعزيز الشعور بالاستقرار النفسي.( Le,2011,P.75 ). فالاستقرار النفسي يعد حالة من التوازن العقلي والجسدي والعاطفي والروحي تمكن الفرد من ادارة او قبول ظروف الحياة ، كما تعني حالة السلام الداخلي التي يمكن يعيشها الفرد بالرغم من تعرضه

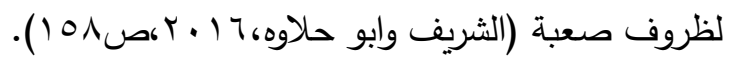


وشعور الفرد بالاستقرار النفسي يجعله قادراً على معرفة ذاته فهو لا يستطيع ان يعرف ذاته دون

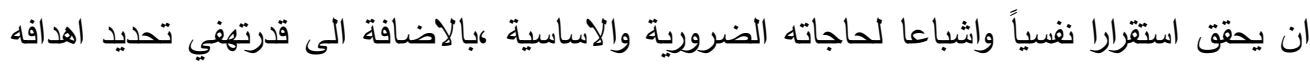
الواقعية التي لاتبتعد عن حدود امكانياته وقدراته، أذ يشير كمال (ب/9 ( ) الى ان الثخصية المستقرة نفسيا والمتوازنة هي التي تتوافق مكوناتها الاساسية بين السلوك والعقل ، كما تتوازن في التفاعلات الداخلية لها وتتكيف مع الظروف الخارجية والحاجات الاساسية لها ، ويصنف الفرد المستقر نفسيا بالنضـ العاطفي والقدرة على التوازن النفسي والانفعالي والثقة بالنفس وبالآخرين

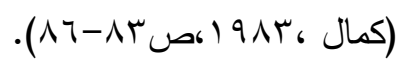
ويذكر بوبلي (· ( . . ان الصحة النفسية الايجابية هي الأساس في بناء الاستقرار النفسي الذي يعد

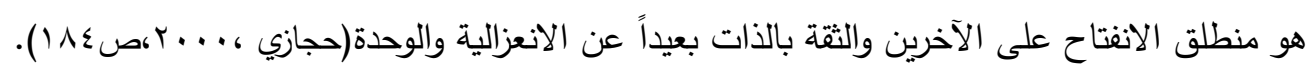
وتثير نتائج العديد من الدراسات الى علاقة الاستقرار النفسي بمتغيرات نفسية عدة ففي دراسة (الديعي، +..r) أشارت النتائج الى وجود علاقة ارتباطية موجبة بين الاستقرار النفسي والهوية الاجتماعية والتصنيف الاجتماعي لدى طلبة الجامعة ، وعدم وجود فروق في العلاقة بين المتغيرات

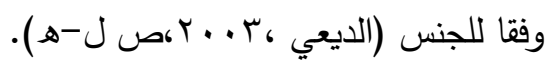

كما بينت نتائج دراسة (الخزرجي، ج . . إ) الى وجود علاقة ارتباطية موجبة بين الاستقرار النفسي

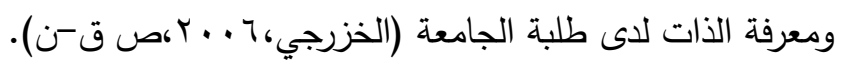
وكذلك توصلت نتائج دراسة (عبيد، ج · ·) الى وجود علاقة ارتباطية بين فاعلية الذات والاستقرار

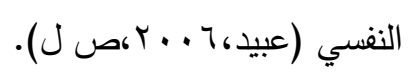

وبينت نتائج دراسة (الخالدي، ع ا ـ r) الى وجود علاقة ارتباطية بين الوعي بالذات والاستقرار النفسي

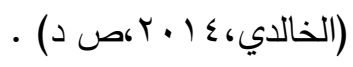

ومما تقدم فأن أهمية البحث الحالي تكمن بما يأتي :- اهمن ا- تتاول متغيرين اساسيين يعدان من المؤشرات التتبؤية للصحة النفية اذ يشيران الى ما يتمتع به

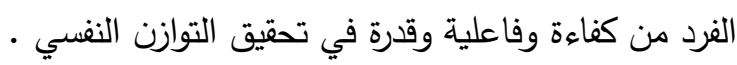
r- أهمية متغيرات الدراسة وتأثيرها على شخصية الفرد وسلوكه. r- تبرز أهمية البحث الحالي في المرحلة العمرية التي يتتاولها البحث وهي مرحلة الثباب والمتمثلة بطلبة الجامعة التي لها دور اساسي في بناء المجتمعات لذا يجب ان يتمتعون بكل المؤشرات الايجابية للصحة النفسية . لصكية 


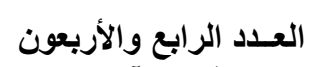

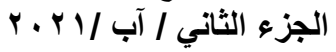
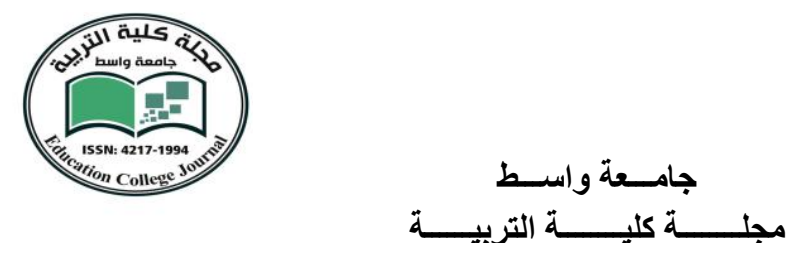

أهداف البحث

يهدف البحث الحالي الى تعرف:

1 - تسامي الذات لدى طلبة الجامعة

r- الاستقرار النفسي لاى طلبة الجامعة

ץ- العلاقة الارتباطية بين تسامي الذات والاستقرار النفسي لاى طلبة الجامعة

ع- الفرق في العلاقة الارتباطية بين تسامي الذات والاستقرار النفسي وفقا لمتغيري الجنس (ذكور -

$$
\text { حدود البحث) والتخصص (علمي ـانساني) - }
$$

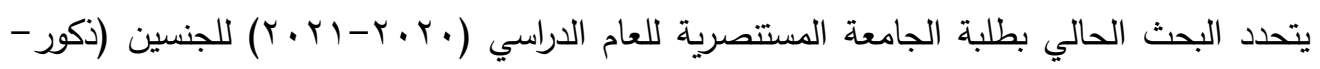
أناث) وللتخصصين (علمي- انساني) للدراسة الصباحية . تحديد المصطلحات اولا: تسامي الذات

عرفته ريد (Reed 2003)

هو امكانية الغرد في توسيع حدوده في المجالات الاتية ،داخل الثخصية فيما يتعلق بالذات الشخصي، ومن خلال علاقاته مع الاخرين فيما يتعلق بالذات الاجتماعي ، ومن خلال دمج الحاضر بالماضي من أجل اعطاء معنى للحاضر فيما يتعلق بالذات الروحي والزمني.(Reed,2003,p.176) وقد تبنت الباحثة تعريف( Reed 2003 تعريفا نظريا اضافة الى اعتمادها نظريتها في اعداد مقياس تسامي الذات . التعريف الاجرائي: هو الدرجة الكلية التي يحصل عليها الطالب من خلال اجابته على مقياس تسامي

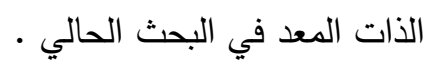
ثانيا:- الاستقرار النفسي

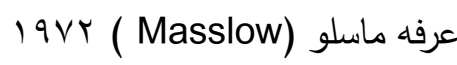
هو وصول الفرد الى حالة من السلام والطمأنينة ، وذلك من خلال تواجده في بيئة آمنة يحكمها نظام وحصوله على عمل يشعره بالاستقرار ، وايمانه بوجود قيم روحية اضافة الى تقبل الذات والتلقائية

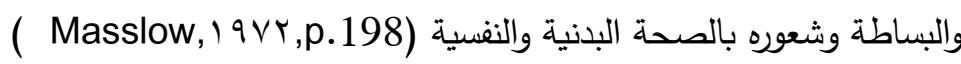
وقد تبنت الباحثة تعريف (Masslow, I qVY) تعريفا نظريا أضافة الى اعتمادها نظريته اطارا نظريا في البحث الحالي .. 
التعريف الاجرائي: هو الدرجة الكلية التي يحصل عليها الطالب من خلال اجابته على مقياس

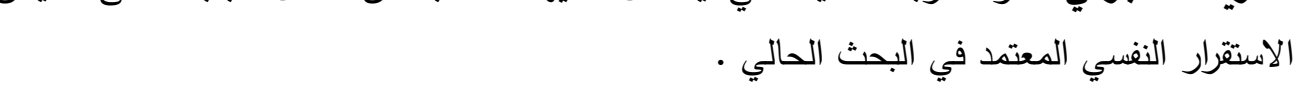

\section{الفصل الثاني}

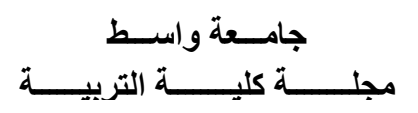

الاطار النظري

اولاًَ- مفهوم تسامي الذات النظي

أن تسامي الذات يعد ظاهرة أنسانية أذ يتميز الوجود الانساني بظاهرتين أنسانية الاولى منها

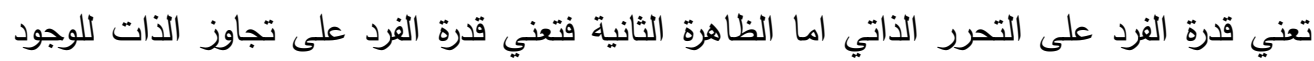

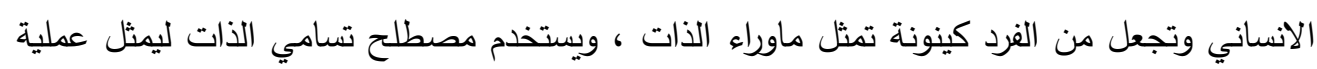

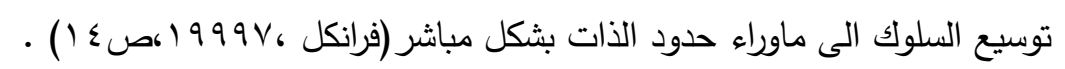

وقد تأثر مفهوم تسامي الذات بنظريات التطور الثخصي في مجال علم النفس الانساني فهو يدل

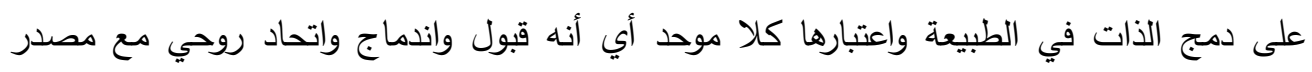

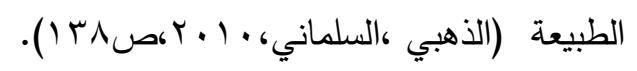

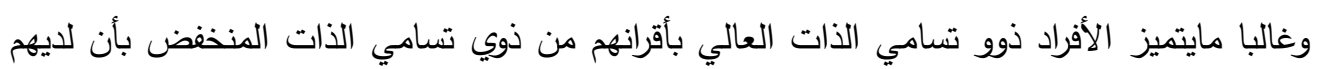

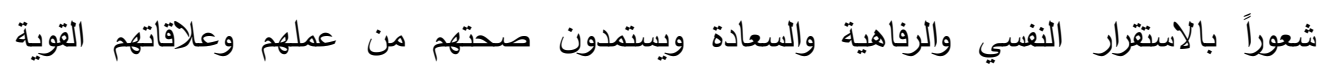

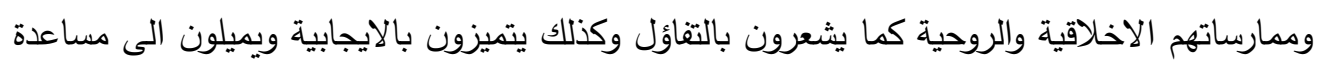
الآخرين وخدمتهم التي يعدوها مصدر سعادة لهم وتضفي على حياتهم رضا ومعنى لأنهم يبتعدون

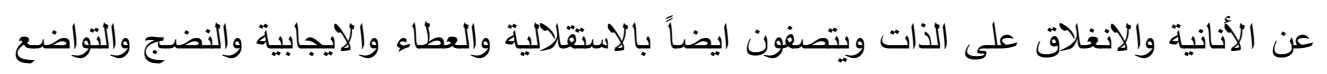
والتسامح ( wong,2016,p.146 ). أن تتمية مفهوم تسامي الذات يجعل الفرد أرقى واقوى وأسمى من كل مايواجهه من مشكلات

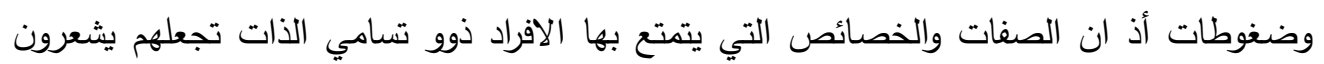

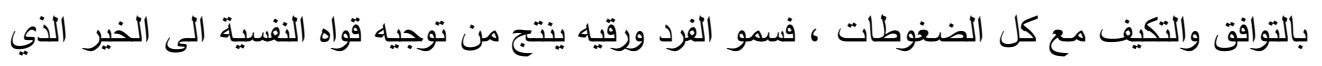
يجعل منه انسانا نقيا صافيا ومتواضعا مما يقوده الى السمو ، أي تطوير الطاقة البايلوجية (المادة)

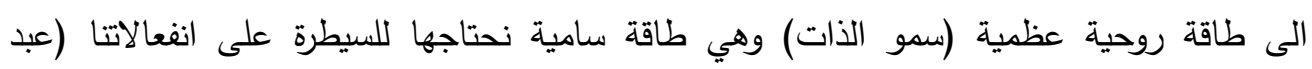

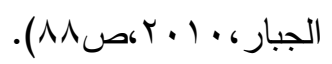




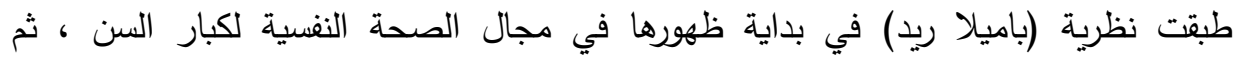
اصبحت تطبق على نطاق اوسع ولكل مراحل الحياة بدأ من مرحلة المراهقة الى مرحلة البلوغ

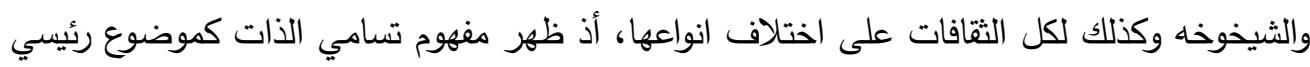
في تخصصات عده منها علم النفس. وتثير ريد Reed الى أن تسامي الذات يتم من خلال مساعدة الفرد للاخرين ويمكن تطويره من خلال

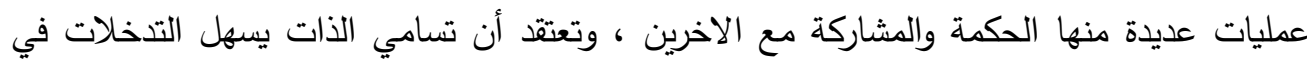

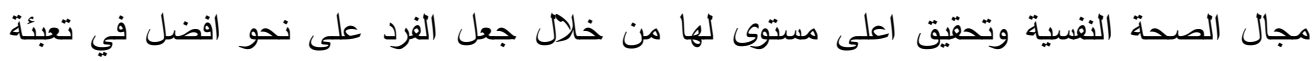

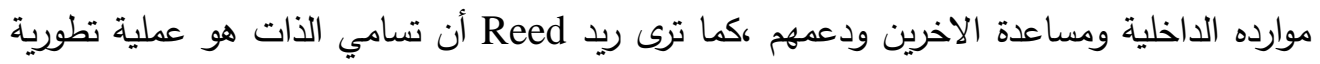

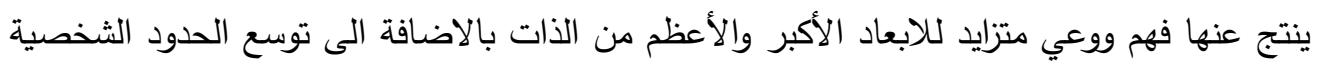
والمتمثلة بداخل الثخصية وبين الثخصية، وان الفرد يتطور بشكل كبير من خلال احداث الحياة

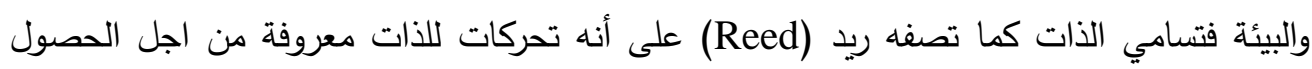

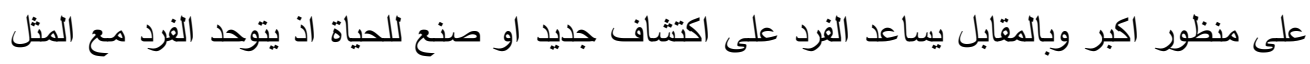

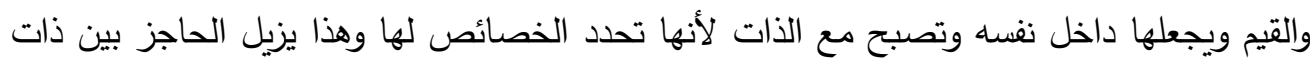

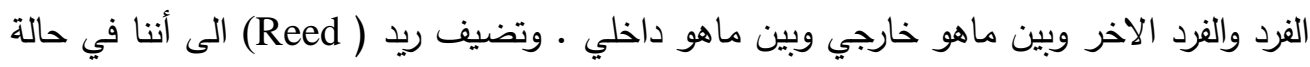

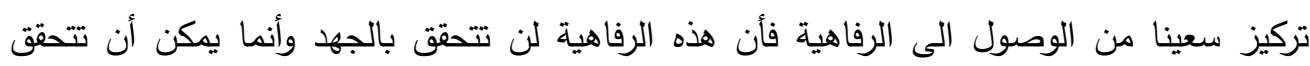

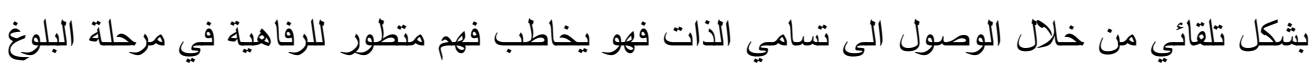

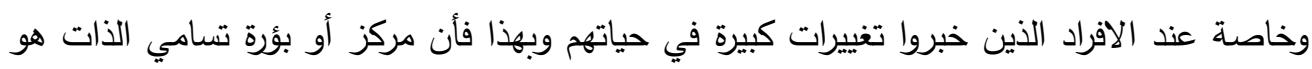

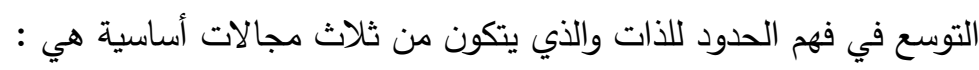

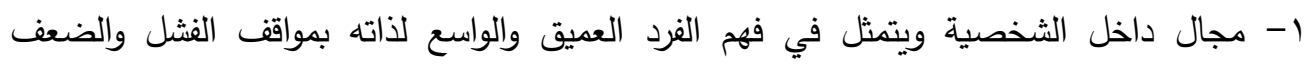
والثعور بالمعاناة ويشمل هذا المجال القيم، التأمل ، الارتقاء نحو الكمال الروحي والنفسي.

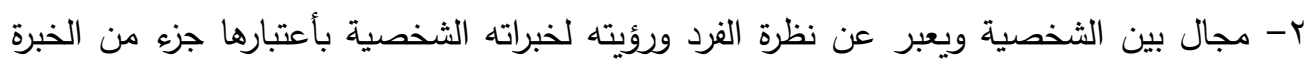
الانسانية الواسعه ويشمل هذا المجال التسامح والايثار والتفاعل ومشاركة الاخرين افراحهم واحزانهم مشاركة وجدانية ايجابية. r- مجال الدنيوية ويمثل الانفتاح الواسع والواعي على الافكار والاحاسيس ويشمل الحب والصدق والفضيلة فهو يعني تجاوز الذات من الوصول الى الكمالية (Reed,2003,p.43). 
العزد الرغابع والأربعون

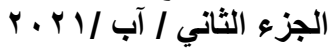

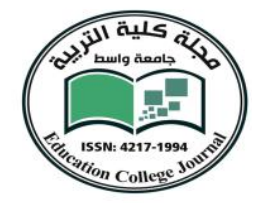

وقد تبنت الباحثة نظرية ريد (Reed2003) اطاراً نظرياً لتفسير تسامي الذات كونها قدمت تصوراً واضحاً لمفهوم تسامي الذات من خلال مجالاته الأساسية التي تم طرحها في هذه النظرية .

\section{ثانيا:- مفهوم الاستقرار النفسي}

يعد الاستقرار النفسي من أبرز علامات الصحة النفسية للفرد أذ يشعره بالسعادة الاخلية والرضا

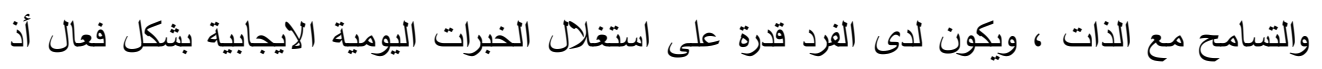
تفتح له آفاقاً جديدة وتسمح لله ايضا بأكتساب الخبرات الجديدة والمختلفة، ويظهر الاستقرار النفسي في سلوك الفرد الفطري من خلال الاستجابات السوية والصحيحة مع الاخرين من جهة ومع ذاته من جهة اخرى بالاضافة الى تفاعله الايجابي والمهم مع المؤثرات المعنوية والمادية وأندماجها مع مشاعره

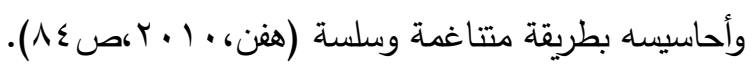
أن الاستقرار النفسي يعد مطلبا أساسيا لكل الافراد من أجل التعايث الصحيح مع المجتمع ومع ذاته ، أذ يعد الاستقرار النفسي حالة نسبية تختلف من شخص الى آخر ومن مجتمع الى آخر وقد تختلف

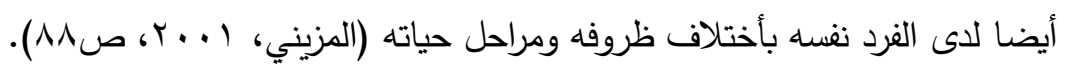
وهناك العديد من العوامل التي تساعد الفرد في الحصول على الاستقرار النفسي منها :ا- بناء أساس نفسي قوي أتجاه الافكار غير الايجابية التي تعمل على زعزعة الاستقرار النفسي للفرد

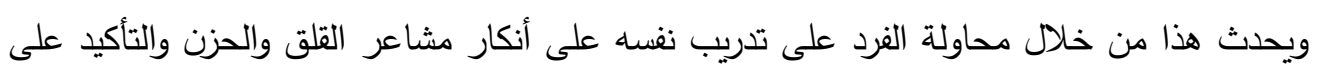

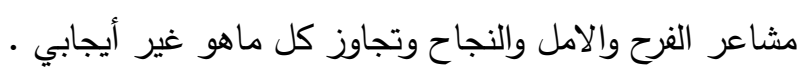
ץ- أن يحدد الفرد أهدافه في الحياة والغرض الذي يسعى الى تحقيقه فهذا الهدف هو الذي يحدد سير حياته ويزيد من مستوى دافعيته للأنجاز وتجاوز الصعوبات التي يمكن أن تواجهه، فالفرد الذي يعيش وليش بدون هدفا يشعر بالضياع ويكون عرضة للقلق وهذا يزيد من شعوره بعدم الاستقرار .

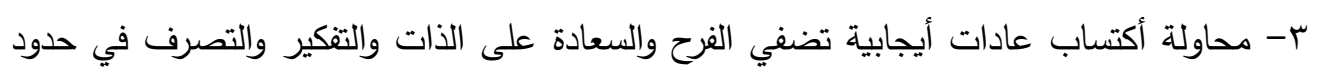
هذه العادات . ع- العفو والتسامح والاعتذار هي مشاعر تضفي على الطاقة الايجابية وتجعل الفرد يشعر بكامل

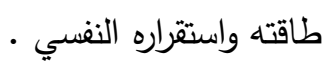
ه- الاعتراف بالقدرات والامكانيات التي يمتلكها الفرد نفسه والمضي في حياته على وفق هذه الامكانيات والابتعاد عن تقليد الاخرين التي يمكن أن تقوده الى الفشل والاحباط في حالة عدم أمتلاكه

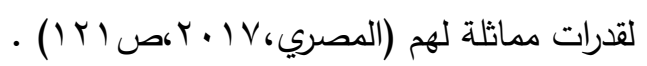


يرى ماسلو في نظريته الهرمية للحاجات الانسانية بأن تلك الحاجات الانسانية لاتتساوى في لانيه

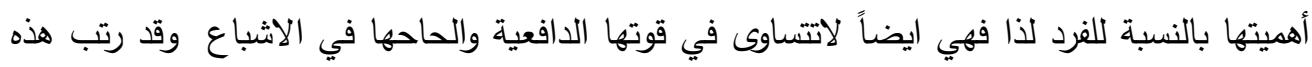

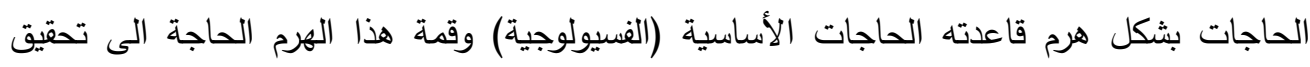

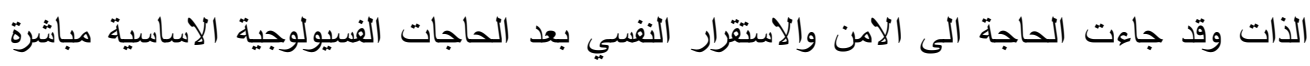

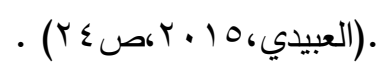

أذ يرى ماسلو أن الفرد الذي يعيش في بيئة مضطربة تفتقر الى الاستقرار والأمان تجعله يشعر بالقلق

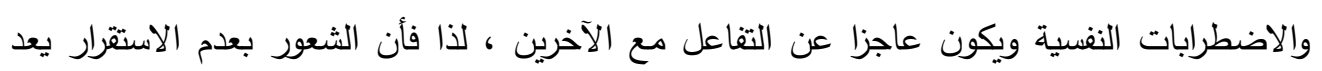

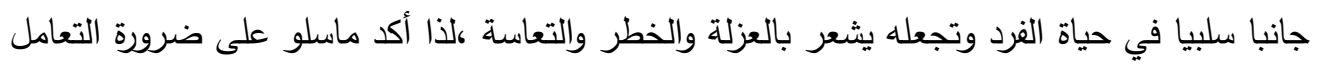

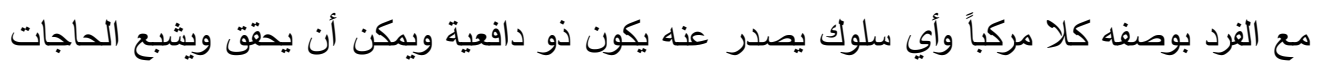
في الوقت ذاته . ويثير ماسلو الى أن الحاجة الى الأمن والاستقرار هي من الحاجات النفسية المهمة وكذلك من أهم

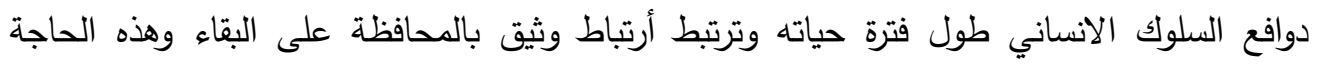

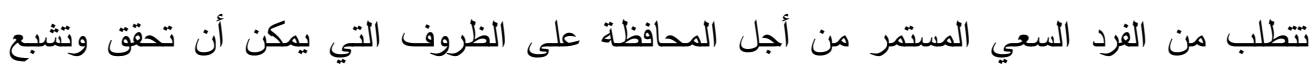
حاجاته وكذلك فهي تهدف الى تطوير مستقبل الفرد من أجل أستثمار طاقاته وأمكانياته نحو ماهي الهو أفضل . يرى ماسلو ان الفرد يسعى الى تحقيق الحاجة الى الاستقرار النفسي وذلك عن طريق وجوده داخل

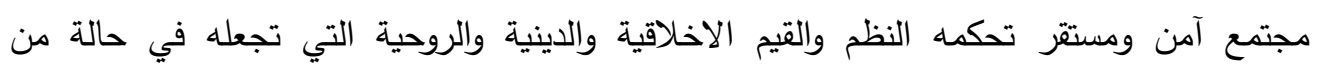
الاستقرار والطمأنينة فثعور الفرد بالسعادة والاستقرار النفسي يعتمدان على مستوى الحاجات التي ولئي

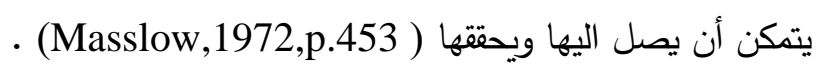
وقد تبنت الباحثة نظرية (ماسلو كونها نظرية شاملة وموسعه في تفسير الحاجة الانسانية المهمه هي الحاجة الى الامن والاستقرار . 


\section{الفصل الثالث}

\section{جامسـعة واســـ

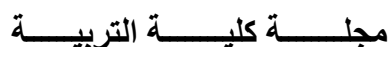

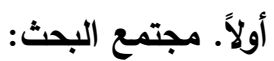

يشمل مجتمع البحث الحالي طلبة كلية التربية في الجامعة المستصرية للعام الدراسي

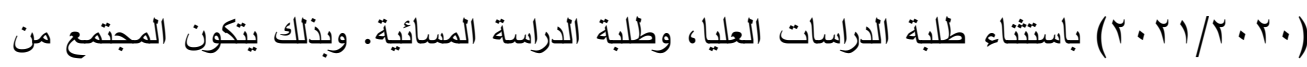

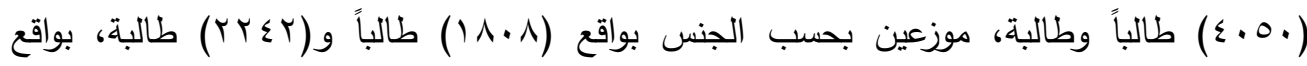

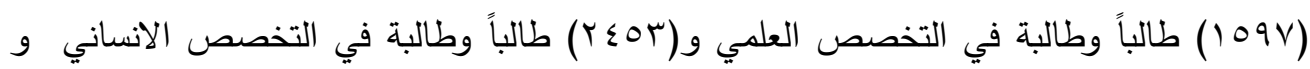

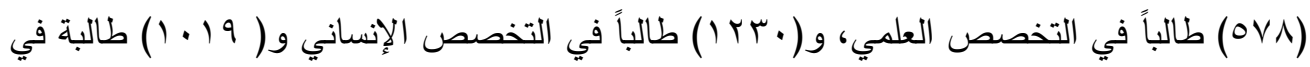

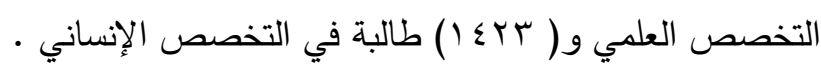
ثانيا- عينة البحث: - n

اتبعت الباحثة اسلوب الطريقة العشوائية البسيطة في أختيار عينة البحث من طلبة كلية التربية

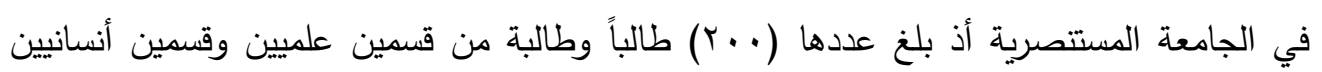

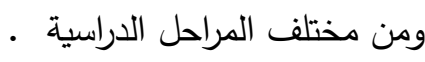
أداتا البحث:

لغرض تحقيق أهداف البحث لابد من وجود أداتين يتوفر فيهما الصدق والثبات والتميز ، وتعد أداتا

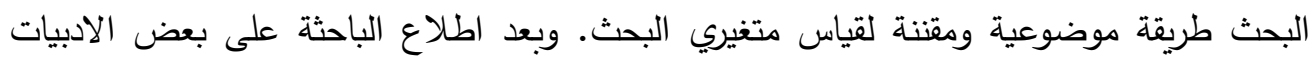

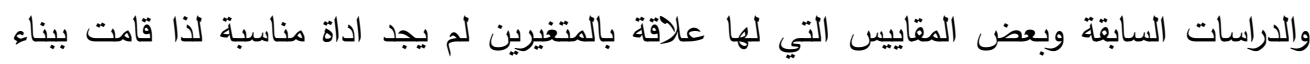

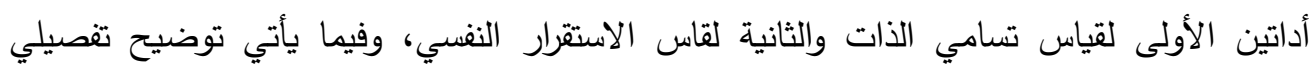

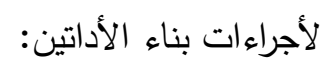
اولاً - مقياس تسامي الذات:

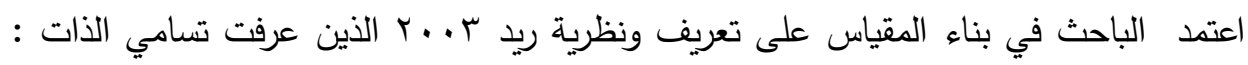

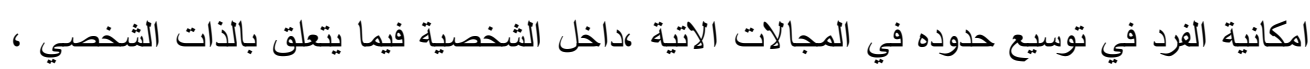

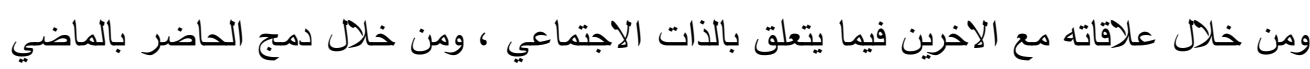

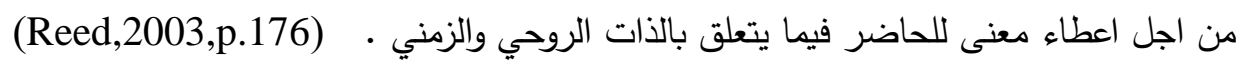
أ- إعداد فقرات المقياس بصيغتها الأولية:

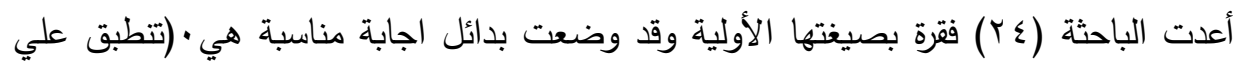
بدرجة كبيرة جدا، تنطبق علي بدرجة كبيرة ، تنطبق علي بدرجة متوسطة، تتطبق علي بدرجة قليلة 
العـدـد الرابع والاربعون

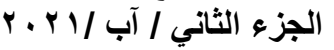

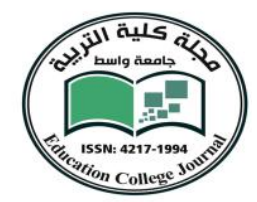

لاتتطبق علي ابدا) وحددت درجات التصحيح (0-ع-ب-r-1) على التوالي .للفقرات الايجابية وبالعكس للفقرات السلبية ) للفقرات السلبية. ب- إعداد تعليمات المقياس: أعدت الباحثة تعليمات المقياس التي تضمنت كيفية الإجابة عن فقراته ، وحث المجيب على الدقة في الإجابة ، وأخفى الهدف من المقياس كي لا يتأثر المجيب به عند الإجابة. ج- وضوح التعليمات وفهم العبارات:

طبقت الباحثة المقياس على عينة مكونة من ( • (ب) طالباً وطالبة موزعين بالتساوي على الجنسين

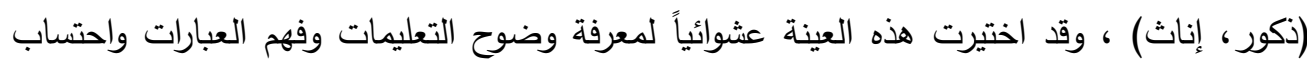

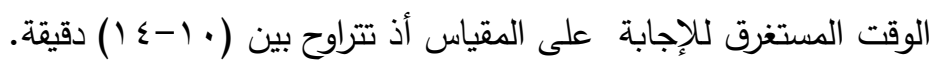
التحليل الإحصائي للفقرات:

قامت الباحثة بتحليل الفقرات التي أعدت لقياس تسامي الذات والبالغ عددها (ع r) فقرة أحصائياً

$$
\text { بهدف حساب قوتها التميزية ومعاملات صدقها . }
$$

بعد تطبيق المقياس على عينة التحليل الإحصائي والبالغ عددها ( . ع) طالبا وطالبة من طلبة كلية التربية قامت الباحثة باستخراج القوة التمييزية لمقياس تسامي الذات وكالآتي:. أسلوب المجموعتين الطرفيتين: وقد تم أتباع الخطوات التالية: 1. تحديد الدرجة الكلية لكل استمارة من الاستمارات البالغ عددها ( . . ؛) استمارة. r. ترتيب الاستمارات من أعلى درجة إلى أدنى درجة.

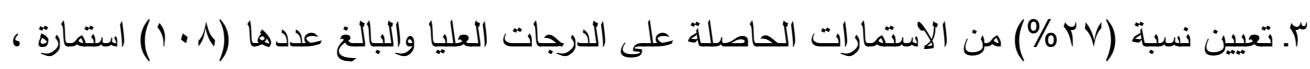

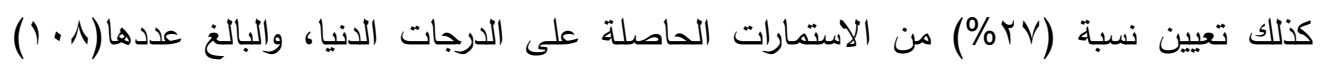

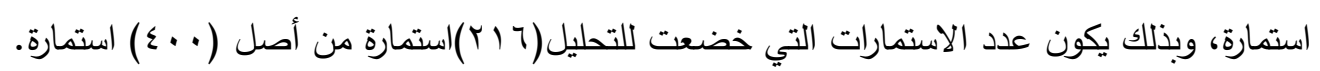
ع. تطبيق الاختبار التائي (t-test) لعينتين مستقلتين لاختبار دلالة الفرق بين المجموعتين العليا والدنيا على كل فقرة، وقد كانت جميع الفقرات مميزة لأن القيمة التائية المحسوبة أكبر من القيمة

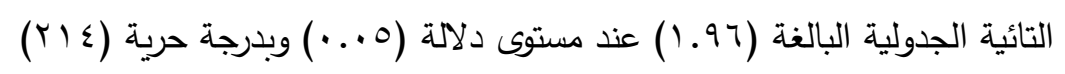
علاقة الفقرة بالارجة الكلية للمقياس:

أُستعمل معامل ارتباط بيرسون لإيجاد العلاقة بين درجة كل فقرة والدرجة الكلية للمقياس، وقد كانت قيم معاملات ارتباط درجة الفقرة بالدرجة الكلية للمقياس دالة إحصائياً لدى مقارنتها بالقيمة

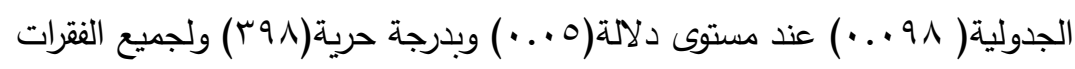


اعتمدت الباحثة صدق البناء من خلال مؤشر علاقة درجة الفقرة بالدرجة الكلية للمقياس. r- الثبات : تم حساب الثبات بطريقتين هما: أ. الاختبار وإعادة الاختبار (الاتساق الخارجي :

قامت الباحثة باستخراج معامل الثبات بهذه الطريقة بعد تطبيق المقياس على الافراد انفهه بفاصل زمني (ع ا ) يوما بين الاختبارين كتم حساب معامل ارتباط (بيرسون) بين درجات أفراد عينة الثبات والبالغ عددها (• ج) طالبا وطالبة في التطبيقين الأول والثاني إذ بلغت قيمة معامل الثبات لمقياس تسامي الذات (YA.. ) وعند مقارنتها بقيمة المعيار المطلق من خلال تربيع معامل الارتباط وقد بلغ (VV, · · ) وهو معامل ثبات جيد عند مقارنته بالدراسات السابقة .

ب ـ معادلة الفا كرونباخ (الاتساق الداخلي): ولحساب الثبات بهذه الطريقة تم أستخدام معادلة (ألفا كرونباخ) إذ بلغ معامل الثبات بالنسبة لمقياس تسامي الذات (1/. •) وهو معامل ثبات جيذ بعد مقارنته بالدراسات السابقة وكما يرى الخبراء والمتخصصون في القياس •

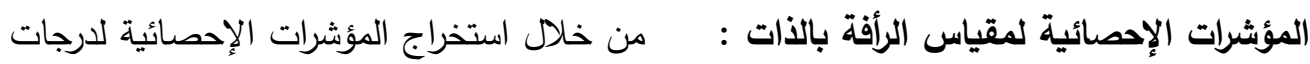
استجابات عينة البحث. تبين أن توزيع درجات عينة التحليل الإحصائي في مقياس تسامي الذات

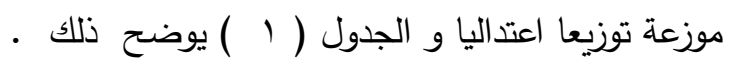
جدول (1)

المؤشرات الإحصائية لمقياس تسامي الذات

\begin{tabular}{|c|c|c|}
\hline قيمتها & \multicolumn{2}{|c|}{ المؤشرات الإحصائية الوصفية } \\
\hline 95,426 & Mean & الوسط الحسابي \\
\hline 96.00 & Median & الوسيط \\
\hline 96,21 & Mode & المنوال \\
\hline 12.603 & Std. Deviation & الانحراف المعياري \\
\hline-0.159 & Skewness & الالتواء \\
\hline 0.384 & Kurtosis & التفرطح \\
\hline 67 & Minimum & اقل درجة \\
\hline 102 & Maximum & أعلى درجة \\
\hline
\end{tabular}




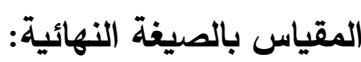

يتكون مقياس تسامي الذات بصيغته النهائية من (عابك) فقرة وبدائل الاجابة هي •(تنطبق علي

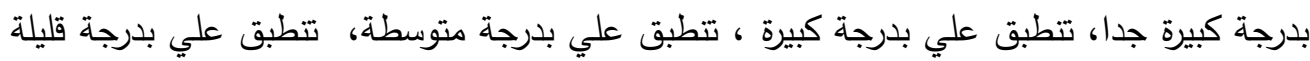

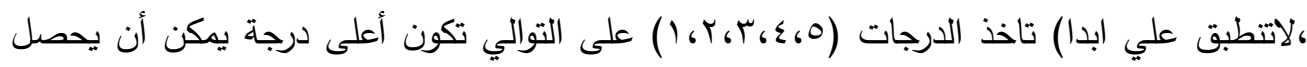

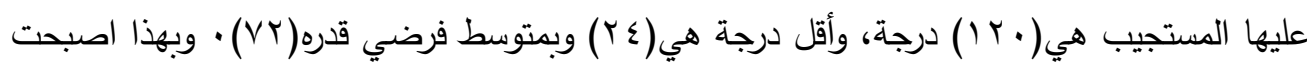
الأداة جاهزة للتطبيق النهائي على عينة البحث .

ثانيا- مقياس الاستقرار النفسي:

بعد الاطلاع على الدراسات السابقة و مراجعة الأدبيات النفسية التي تتاولت الاستقرار النفسي ، الإسئ

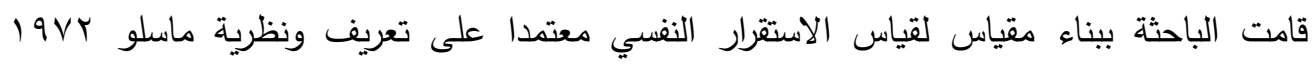

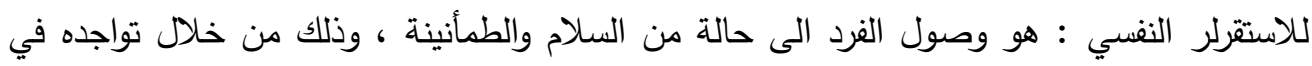

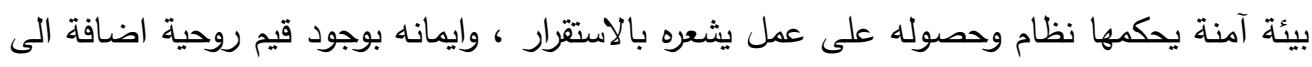

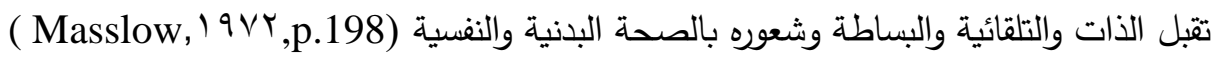
أ - إعداد فقرات المقياس بصيغتها الأولية:

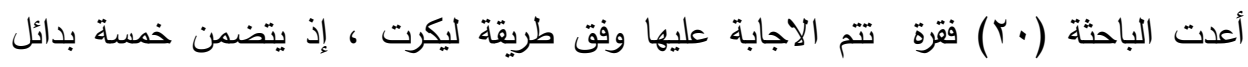

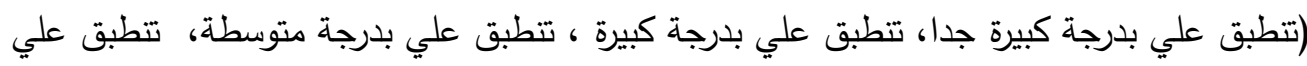

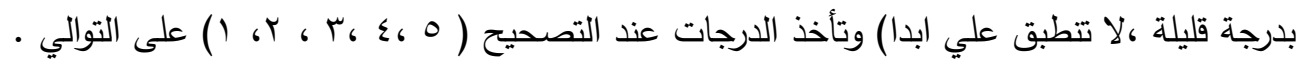
ب- وضوح التعليمات وفهم العبارات: طبقت الباحثة المقياس على عينة مكونة من (ب) طالباً وطالبة موزعين بالتساوي على الجنسين

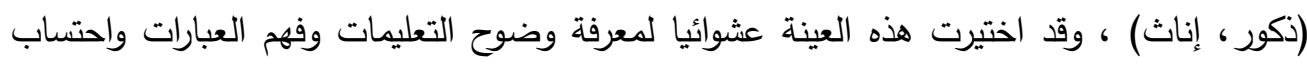

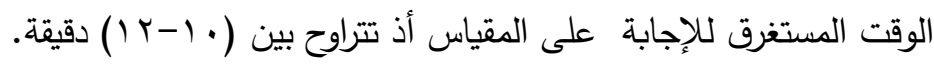
التحليل الإحصائي للفقرات:

قامت الباحثة بتحليل الفقرات التي أعدت لقياس الاستقرار النفسي والبالغ عددها (•r) فقرة

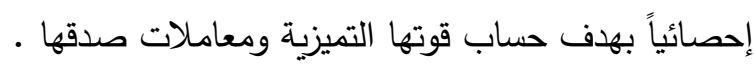

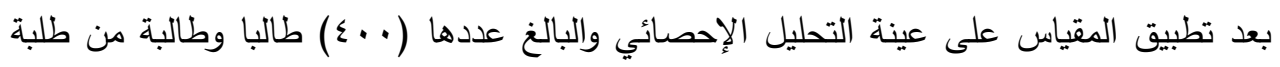
كلية التربية قامت الباحثة باستخراج القوة التمييزية لمقياس الاستقرار النفسي وكالآتي: 


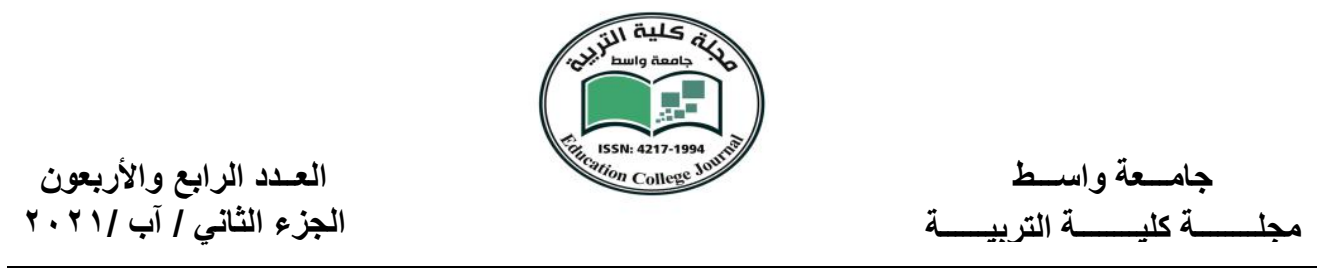

أسلوب المجموعتين الطرفيتين: وقد تم أتباع الخطوات التالية:

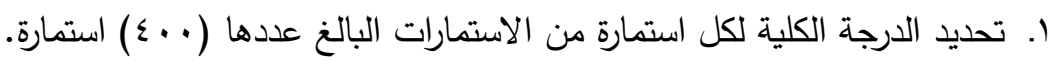
r. ترتيب الاستمارات من أعلى درجة إلى أدنى درجة.

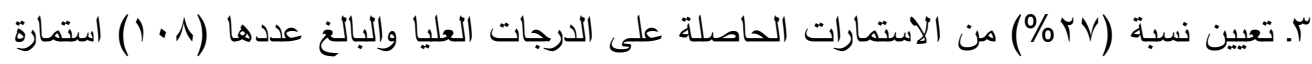

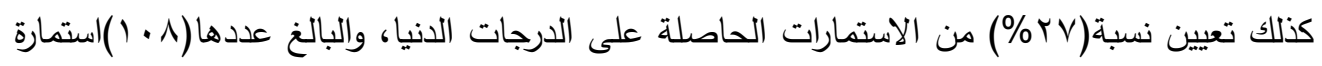

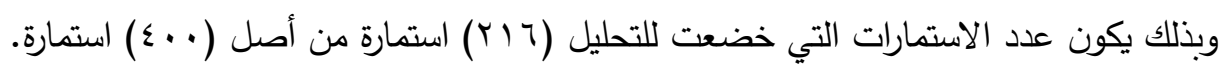

ع. تطبيق الاختبار التائي

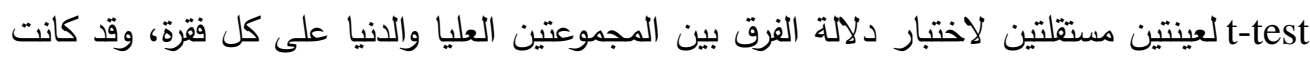

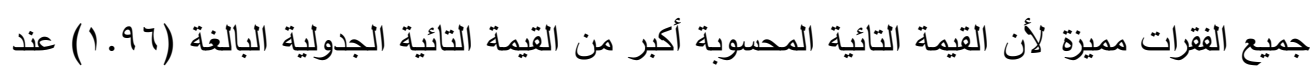

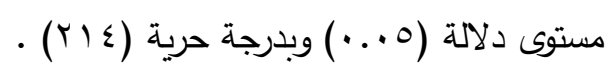

\section{علاقة الفقرة بالارجة الكلية للمقياس:}

أستعمل معامل ارتباط بيرسون لإيجاد العلاقة بين درجة كل فقرة والدرجة الكلية للمقياس، وقداليه

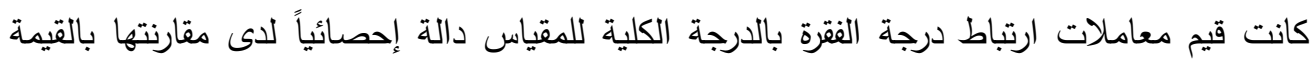

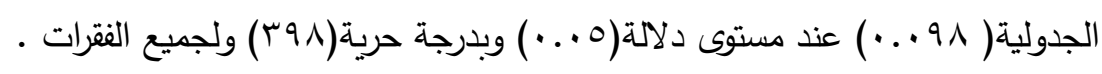

الخصائص السايكو مترية: صدق البناء اعتدت الباحثة صدق البناء من خلال مؤشر علاقة درجة الفقرة بالدرجة الكلية للمقياس.

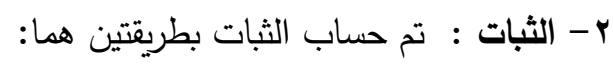

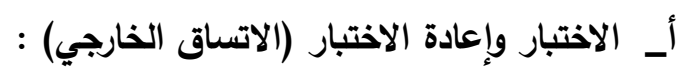

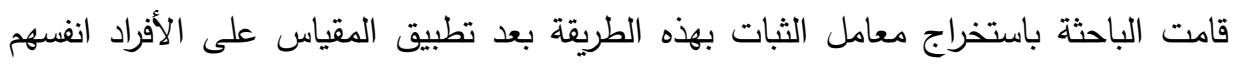
بفاصل زمني (ع () يوماً بين الاختبارين ،تم حساب معامل ارتباط (بيرسون) بين درجات أفراد عينة

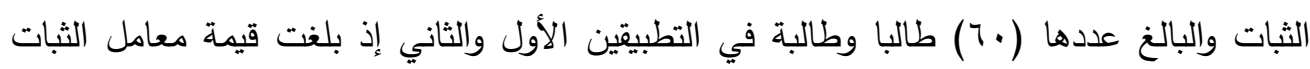

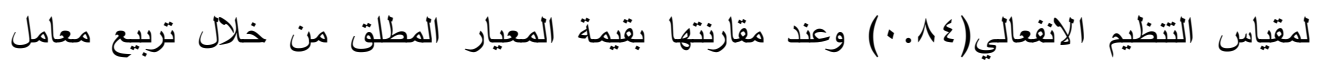

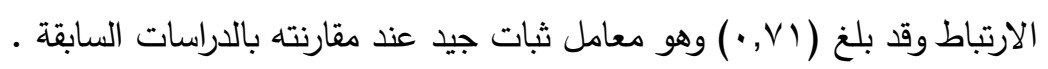


العـد العد الرابع والأربعون

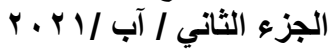

$$
\text { جامسعة واســط }
$$

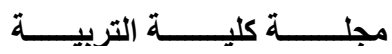

ب _ معادلة الفا كرونباخ (الاتساق الداخلي):

ولحساب الثبات بهذه الطريقة تم أستخدام معادلة (ألفا كرونباخ) إذ بلغ معامل الثبات بالنسبة

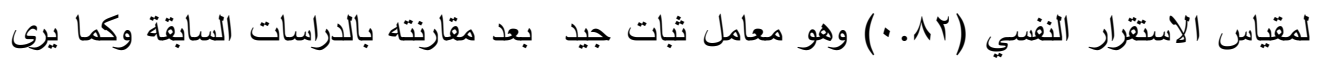

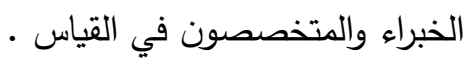

\section{(r) (بدول)}

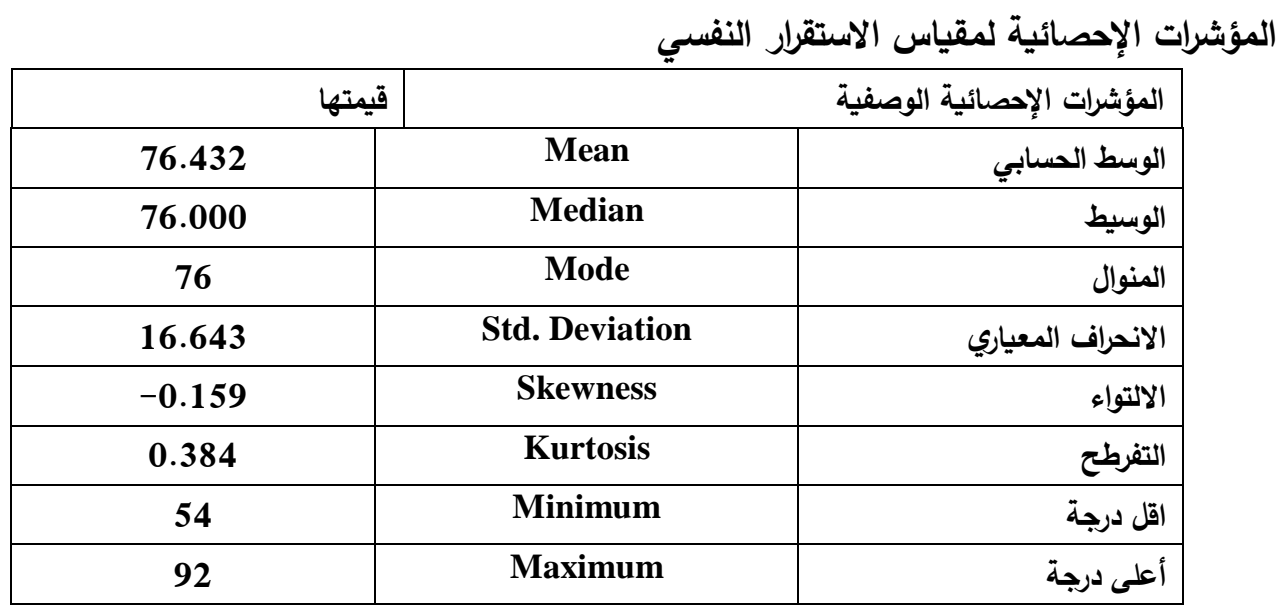

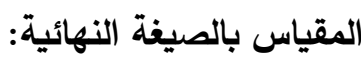

يتكون مقياس الاستقرار النفسي بصيغته النهائية من (·r) فقرة وبدائل الاجابة هي •(تتطبق علي

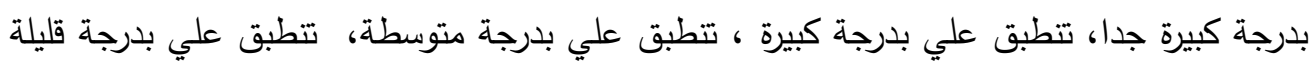

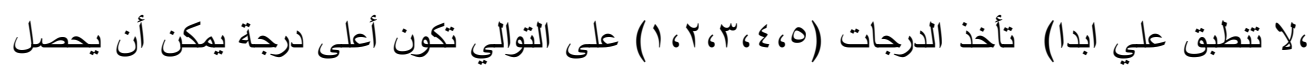

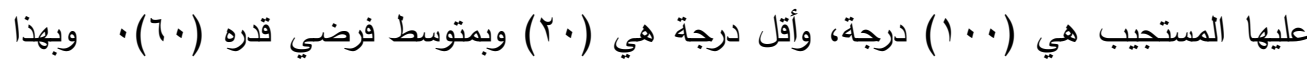
اصبحت الاداة جاهزة للتطبيق النهائي على عينة البحث ـ تم تطبيق المقياس الكترونيا. 
الفصل الرابع:

عرض النتائج وتفسيرها ومناقشتها:

ا. التعرف على تسامي الذات لاى طلبة الجامعة:

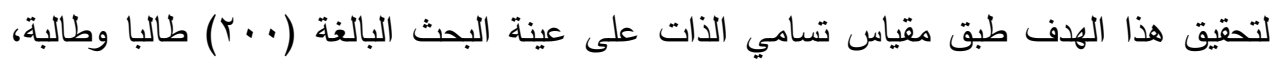

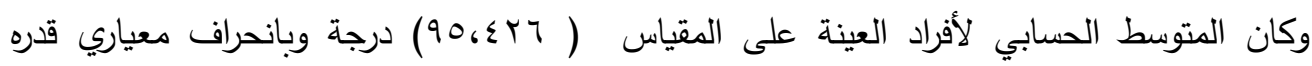

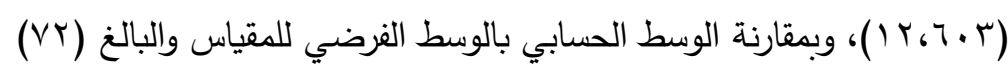

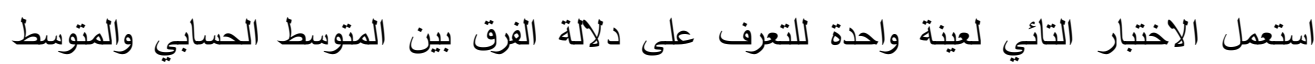
الفرضي للمقياس

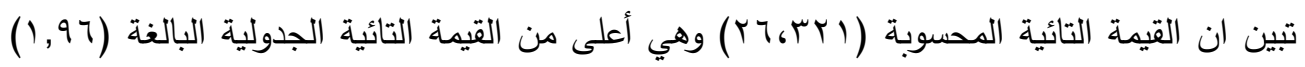

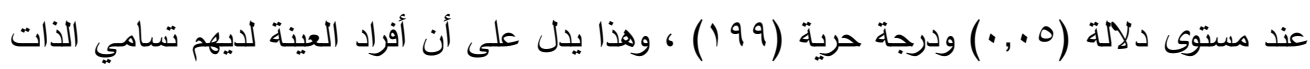
والجدول(r) يبين ذلك .

جدول (r)

الاختبار التائي لدلالة الفرق بين المتوسط الحسابي للعينة والمتوسط الفرضي لمقياس تسامي الذات

\begin{tabular}{|c|c|c|c|c|c|c|c|}
\hline هـ الدلالة & الجديمة التائية & المحسوبة التائية & الحرية & المعياري & الفرضي & الحسابي & العينة \\
\hline دالة & 1.97 & KG,YYI & 199 & r & VY & $90, \leqslant Y 4$ & $r .$. \\
\hline
\end{tabular}

تثير النتائج إلى أن طلبة الجامعة يتمتعون بتسامي الذات وتتفق مع نتائج دراسة( الذهبي والسلماني

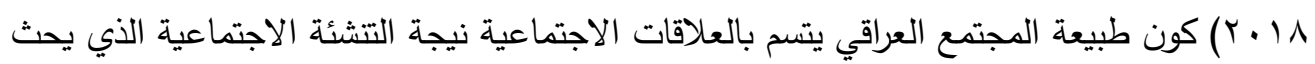

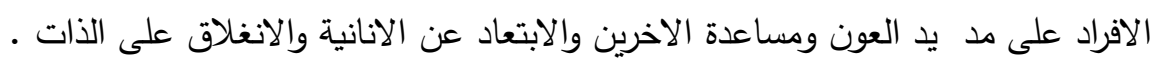

r. التعرف على الاستقرار النفسي لاى طلبة الجامعة:

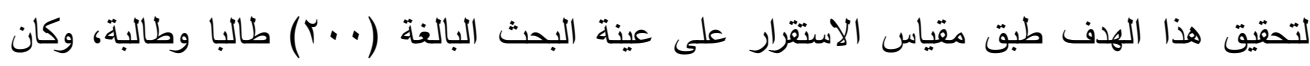

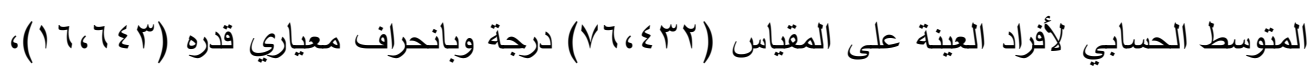
وبمقارنة الوسط الحسابي بالوسط الفرضي للمقياس والبالغ (.7) استعمل الاختبار التائي (T-test)

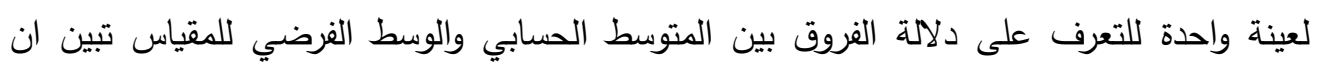




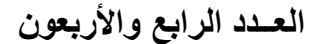

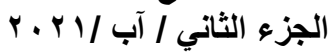

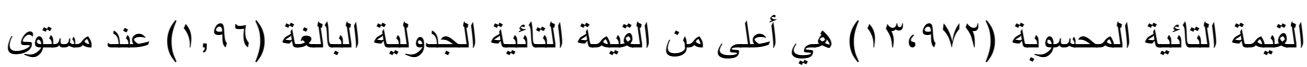
دلالة (0., ••) ودرجة حرية (99 1) ، وهذا يدل على أن أفراد العينة لديهم استقرار نفسي ، والجدول

\section{جدول (؛)}

الاختبار التائي لالالة الفرق بين المتوسط الحسابي للعينة والمتوسط الفرضي لمقياس الاستقرار

\begin{tabular}{|c|c|c|c|c|c|c|c|}
\hline هـ., مستوى الدلالة & القائية & القائية القيمة & الحرجة & الانحراف المعياري & الفرضي & الوسطابي & العينة \\
\hline دالة & 1.97 & Ir.qVY & 199 & $17.7 \leq r$ & 7. & $V T_{6} \leqslant r r$ & r... \\
\hline
\end{tabular}

يتضح من الجدول اعلاه ان طلبة الجامعة لليهم الاستقرار النفسي وذلك لشعورهم بالاستقلالية والنضج والقدرة على تحقيق الاهداف التي يرغبون بها وهذا مايعزز لديهم حالة من الرضا الداخلي والاستقرار

النفسي

r. العلاقة الارتباطية بين تسامي الذات والاستقرار النفسي لاى طلبة الجامعة لتحقيق هذا الهدف استخدم الباحث معامل ارتباط بيرسون لاستخراج العلاقة الارتباطية بين

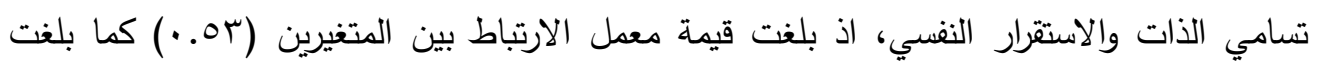

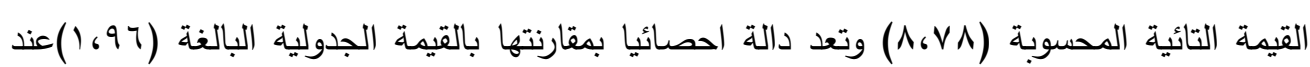
مستوى دلالة( ه . . ) ودرجة حرية (191 (1) وهذا يدل على ان هناك علاقة ايجابية بين تسامي الذات والاستقرار النفسي لاى طلبة الجامعة ، أي كلما ارتفع تسامي الذات لدى طلبة الجامعة ، زاد الاستقرار النفسي والجدول(0) يوضح ذلك 


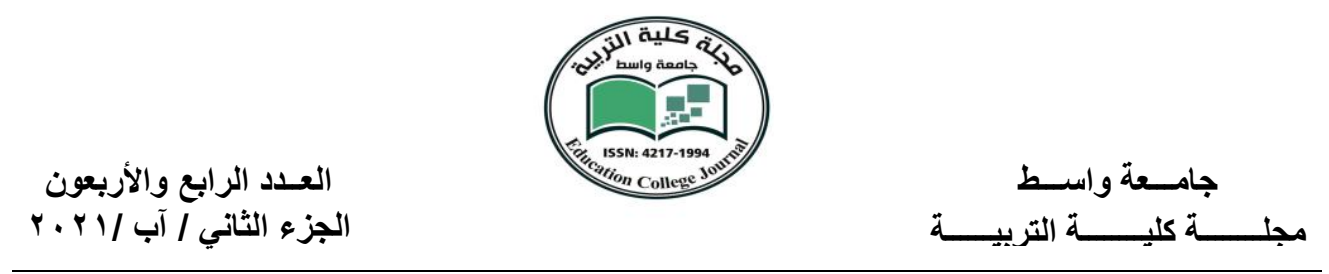

الجدول (o)

معامل ارتباط تسامي الذات والاستقرار النفسي لاى طلبة الجامعة

\begin{tabular}{|c|c|c|c|c|c|}
\hline \multirow{2}{*}{ مستوى الدلالة 0.05} & \multicolumn{2}{|c|}{ القيمة التائية } & \multirow{2}{*}{ معامل الارتباط } & \multirow{3}{*}{ تسامي الذات } & \multirow[b]{2}{*}{ العدد العد } \\
\hline & الجدولية & المحسوبة & & & \\
\hline 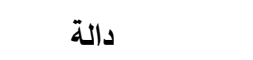 & 1.94 & A.VA & . or & & $r \ldots$ \\
\hline
\end{tabular}

اظهرت النتائج وجود ارتباط ايجابي بين تسامي الذات والاستقرار النفسي لان كلا المتغيرين يعبران

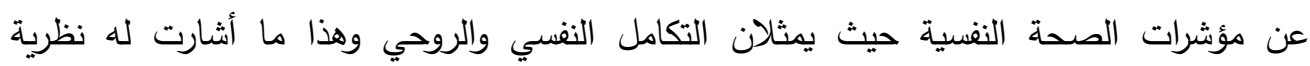

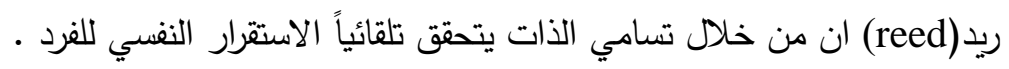

الهاف الرابع: الفرق في العلاقة بين تسامي الذات والاستقرار النفسي لاى طلبة الجامعة تبعاً لمتغير الجنس (ذكور - أناث) والتخصص (علمي - النساني).

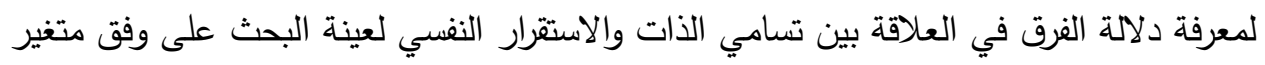

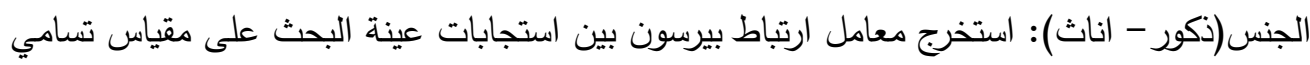

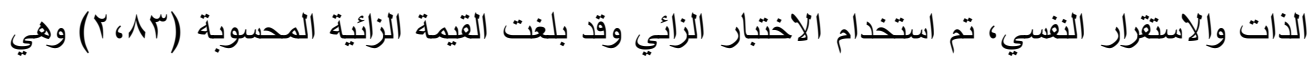

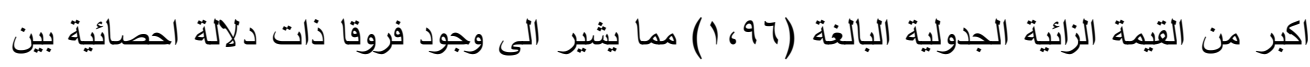

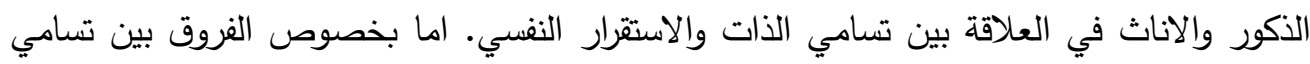

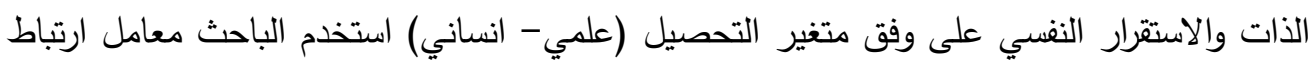

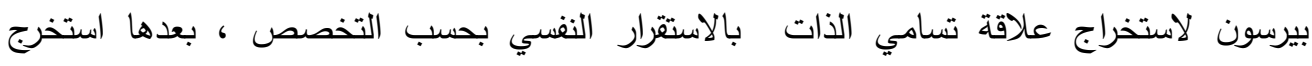

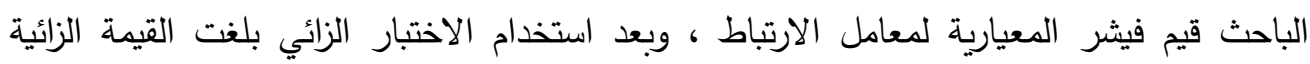

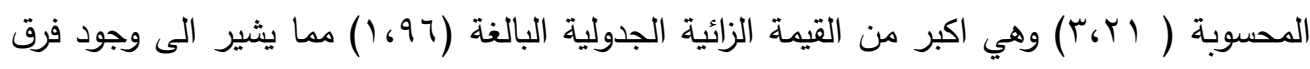

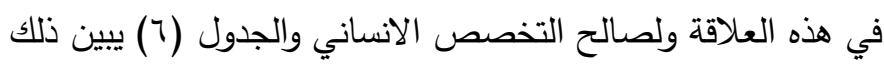




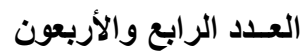

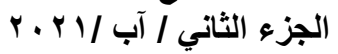
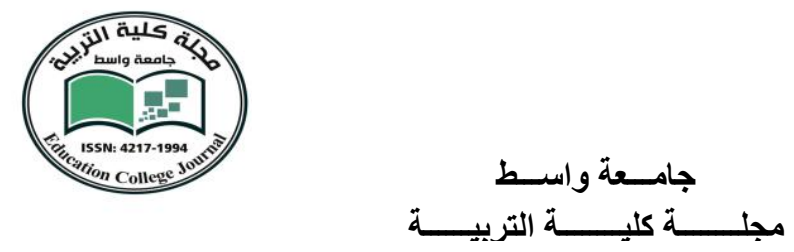

الجدول (†)

دلالة الفرق في معامل الارتباط بين تسامي الذات والاستقرار النفسي لدى طلبة الجامعة تبعا لمتغير الجنس

\begin{tabular}{|c|c|c|c|c|c|c|}
\hline & & & & & & والتخصد \\
\hline \multirow{2}{*}{ 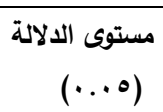 } & \multicolumn{2}{|c|}{ القيمة الزائية } & \multirow{2}{*}{ القيمة المعيارية } & \multirow{2}{*}{ قيمة معامل الارتباط } & \multirow{2}{*}{ العدد الع } & \multirow{2}{*}{ فئات العين } \\
\hline & الجدولية & المحسوبة & & & & \\
\hline \multirow[b]{2}{*}{ دالة } & \multirow[b]{2}{*}{1.97} & \multirow[b]{2}{*}{ r.Ar } & .180189 &. $.1 V r$ & $1 \ldots$ & الذكور \\
\hline & & & $. . \leq 79 \leqslant Y 0$ &.$\varepsilon r v$ & $1 \ldots$ & الإناث \\
\hline \multirow{2}{*}{ دالة } & \multirow{2}{*}{1.97} & \multirow{2}{*}{ r.r. } & $. .+1 \leqslant \wedge 71$ & $\ldots 1 \leq$ & $1 \ldots$ & علمي \\
\hline & & & .001010 & .0 .1 & $1 \ldots$ & انساني \\
\hline
\end{tabular}

أظهرت النتيجة وجود فروق ذات دلالة إحصائية بين معاملي الارتباط لاى طلبة المرحلة

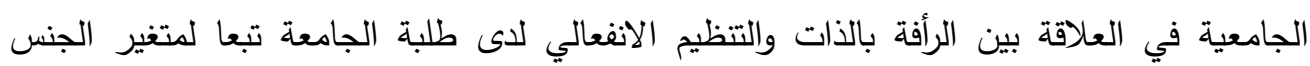

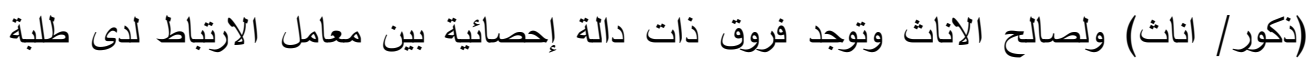

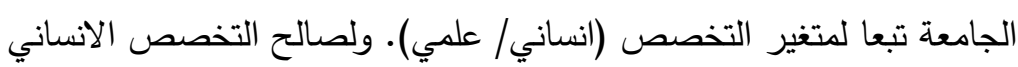

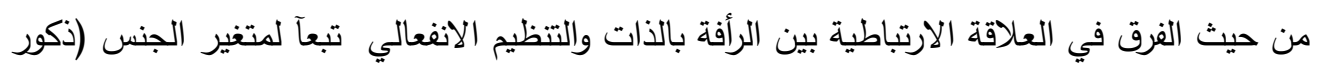

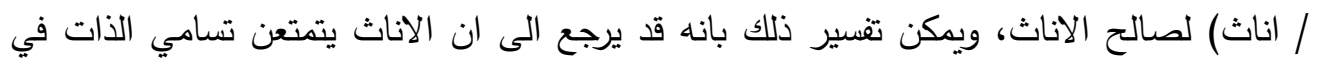

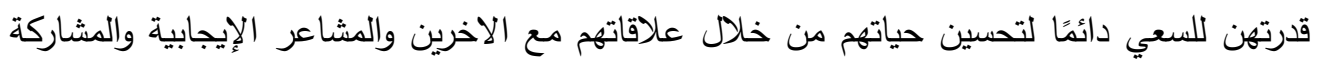

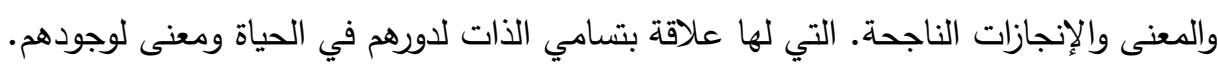

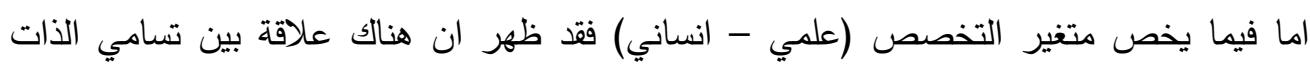

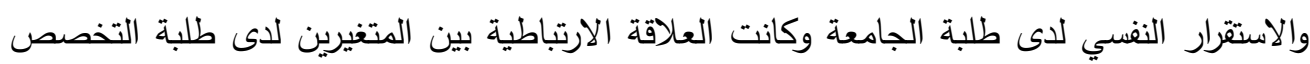

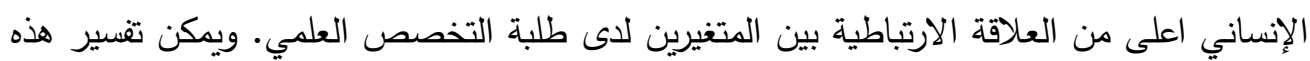

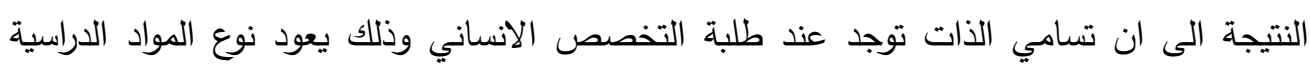

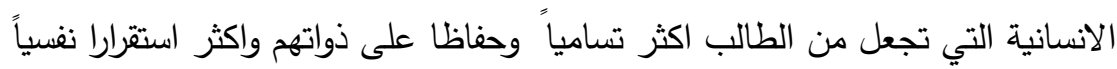




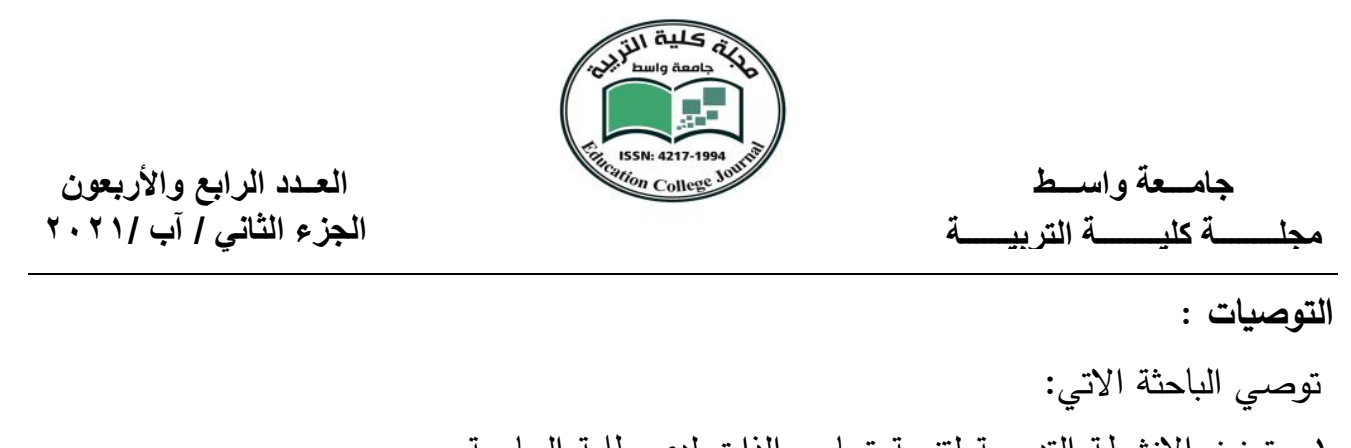

ا- تعزيز الانشطة التدريبية لتنمية تسامي الذات لدى طلبة الجامعة

r- عقد وش عمل تثقيفية لتوعية الطلبة لتعزيز الاستقرار النفسي من اجل مواجهة المشكلات والضغوط النفسية للوصول الى صحة نفسية أفضل.

المقترحات :

1- اجراء دراسة لمعرفة العلاقة بين تسامي الذات والحرية العاطفية لدى طلبة الجامعة ץ- اجراء دراسة للتعرف على السمات الشخصية وعلاقتها بالاستقرار النفسي لدى طلبة الجامعة . ب- اجراءدراسة مماثلة على عينات مختلفة من الطلبة (المتوسطة- الاعدادية- المعاهد)

المصادر

ا- ابراهيم ، سحر حسن ، ( 9 • ب)، العوامل المنبئة باهناء النفسي لاى السيدات المتزوجات ، دراسة نفسية ، رابطة

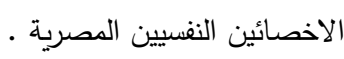

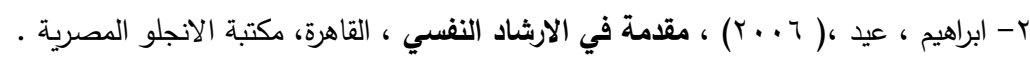

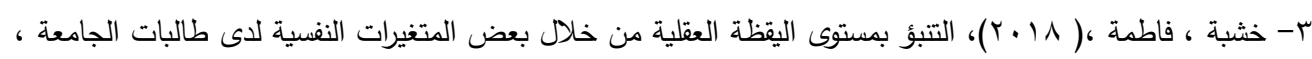

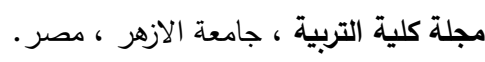

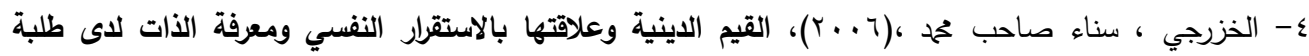
الجامعة ، اطروحة دكتوراه غير منشورة ، كلية التربية ، الجامعة المستتصرية.

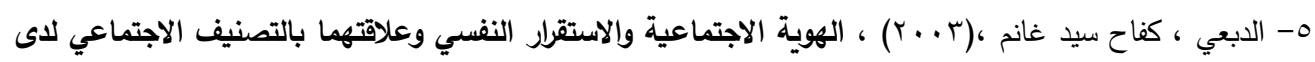

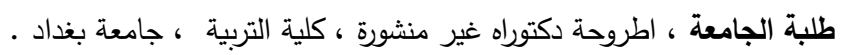

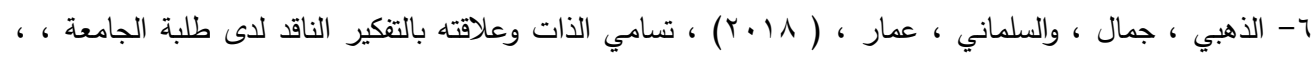

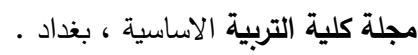

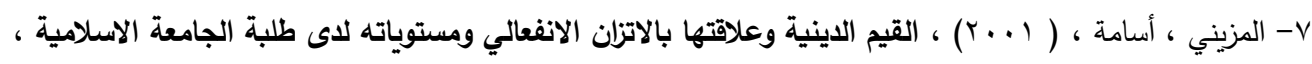

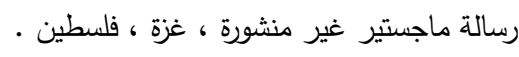

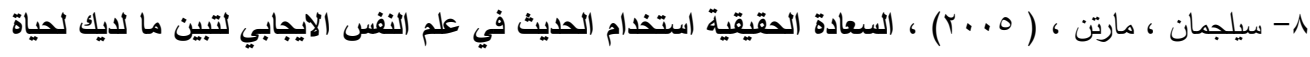

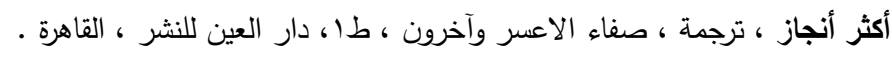

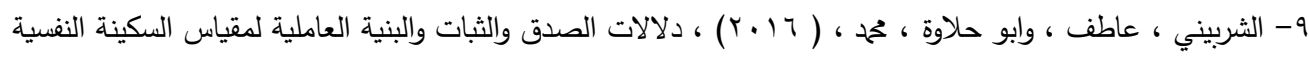

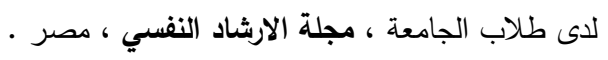


العـدابد الرابع والاربعون

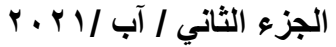

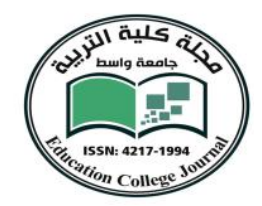

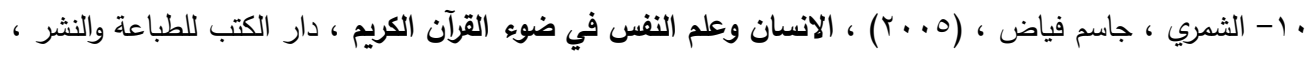

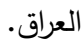

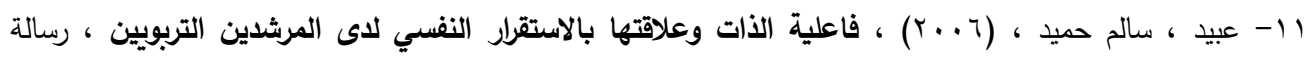

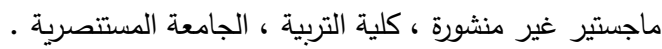

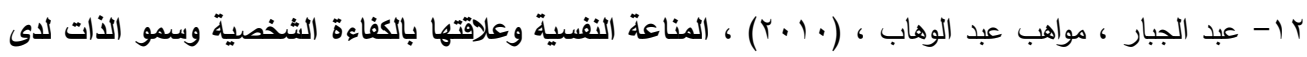

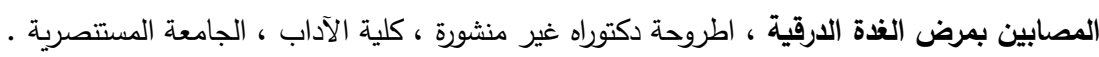

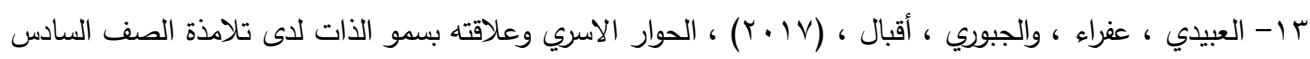

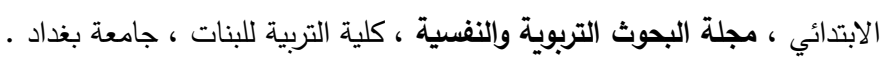

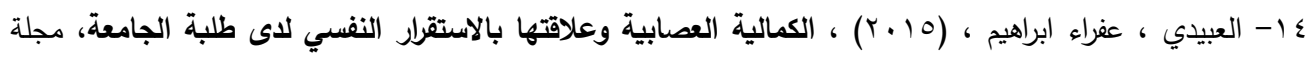

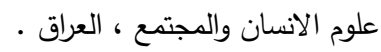
10- فرانكل ، فكتور ، (99 ( 9 ) ، ارادة المعنى اسس وتطبيقات العلاج بالمعنى ، ترجمة ، ايمان فوزي ، القاهرة ، دار زهراء الشرق.

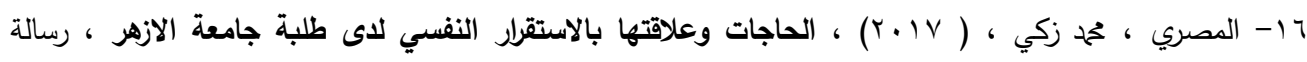

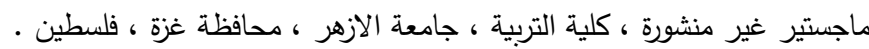

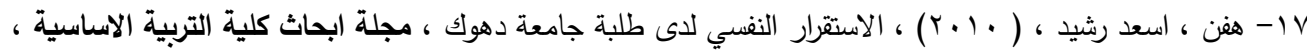

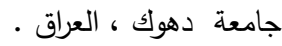

المصادر الاجنبية 1- cloninger,(1993), A.psycholical model of temperament and charcter. Archives of General psychiatry.

2- Haugan,G\&Innstrand,S.T.(2012) Theeffect of self- transcendence ondepression in cognitively,ISRN psychiatry.

3- Le, (2011), Live s Atisfaction,dpenness value self- Transcendence, and widom, Journal of Happiness studies

4- Masslow, (1972) Manual for The security In security Inventory, Pauls Alto calfi consulting Psychologists Press

5- Reed,G (2003) Theory of self - transcendence in ,M.J.smith \&P.Liehr(EDS) middle rang Theory for nursing, New York.

6- Sternberg, R (2003). Wisdom,Intelligence, andcreativity, synthesized . Gambidge, England Gambridge university Press.

7- Wong. P.T.P (2016) Meaning - seeking ,self- Transcendence, and well - being In; Batthyany 